\title{
Effect of Fluoride Releasing Bonding Materials on Shear Bond Strength of Orthodontic Brackets
}

\author{
Duygu Yetkin' (D), Gülşilay Sayar² (D) \\ 'Department of Orthodontics, Bahcesehir University School of Dentistry, İstanbul, Turkey \\ 2Department of Orthodontics, Istanbul Medipol University School of Dentistry, İtanbul, Turkey
}

Cite this article as: Yetkin D, Sayar G. Effect of Fluoride Releasing Bonding Materials on Shear Bond Strength of Orthodontic Brackets. Turk J Orthod 2020; 33(1): 52-8.

\section{ABSTRACT}

Objective: The aim of the present study was to compare the shear bond strength (SBS) of three different fluoride-releasing bonding agents with a conventional adhesive system.

Methods: Eighty-four extracted human premolar teeth were separated into four groups and embedded in acrylic molds consisting of 21 teeth in each group. Brackets were bonded with Transbond XT in group 1, Clearfil SE Protect Bond in group 2, LED Proseal in group 3 , and Opalseal in group 4. After bracket bonding, the teeth were thermocycled 1000 times. SBS test was performed, and Adhesive Remnant Index (ARI) scores of the groups were assessed.

Results: One-way analysis of variance test was used to compare the significant differences between the groups. Chi-square and Fisher's exact tests were used to evaluate ARI scores. The Opalseal group showed the highest bond strength, but there was no statistically significant difference between the groups in SBS values ( $p=0.067$ ). The results of ARI scores were statistically significant.

Conclusions: All bonding materials used in the study showed clinically sufficient bond strengths.

Keywords: ARI, bonding, fluoride, orthodontic brackets, shear bond strength

\section{INTRODUCTION}

It is difficult to maintain oral hygiene when the fixed orthodontic appliances are placed on the teeth. Residual adhesive and rough surfaces of brackets, arch wires, or ligatures may increase bacterial colonization, and tooth demineralization may occur (1). During fixed orthodontic treatment, demineralization is one of the major problems, especially in patients with poor oral hygiene (2-4). The first step of demineralization is white spot lesions (WSLs), and these lesions could be seen clinically exactly 4 weeks after the beginning of orthodontic treatment (5). The frequencies of WSL were reported to be between $2 \%$ and $96 \%$ in orthodontic patients and $25 \%$ in non-orthodontic patients (2-6).

It has been reported that the use of fluoride during orthodontic treatment reduces demineralization (4-6). The uses of fluoride-containing toothpastes, mouthwashes, and gels require patient cooperation, but applications of fluoride-releasing glass ionomer cements, fluoride-added composites, fluoride-releasing bonding agents, fluoroelastomeric ligatures, or fluoride lacquers need no cooperation. The use of fluoride-containing bonding agents during orthodontic treatment is a non-patient-dependent protective action.

In orthodontic direct bonding, acid etchant is used to remove prismatic and interprismatic enamels, and after that a primer (bonding agent) is applied to the enamel to form resin tags. Orthodontic adhesive can penetrate the enamel surface by the aid of a bonding agent $(7,8)$.

Conventional or fluoride-releasing bonding agents can be used in orthodontic bonding. Fluoride-releasing bonding supplies fluoride ions by the aid of the aqueous oral environment, and these ions penetrate the enam- 
el prisms. Fluoride ions transform the hydroxyapatite crystals to fluorohydroxyapatite, and the structure of the enamel becomes more resistant to acid attacks and caries. Therefore, this strong fluorohydroxyapatite barrier may have different effects on the bond strength of orthodontic brackets (9).

The effect of bonding agents on bracket bond strength was previously reported in several studies $(10,11)$. Various brands of bonding agents are present in the market, and bond strength of these agents is critical for orthodontists. Therefore, the aim of the present study was to compare the shear bond strength (SBS) of three different fluoride-releasing bonding agents with a conventional bonding agent. The null hypothesis of the present study was that the fluoride-releasing bonding materials do not have any effect on the SBS of orthodontic brackets.

\section{METHODS}

Sample size estimation was performed prior to the study using the G*Power 3.0.10 software with a $95 \%$ confidence interval $(\mathrm{Cl})$ and a of 0.05 to detect a significant difference of $1 \mathrm{MPa}$ in SBS value, and it was determined that to have a power of $80 \%$, there should be 19 teeth in each group (12). According to sample size estimation, 84 human first premolar teeth were used in the present study, meaning that 21 teeth were included in each group. Inclusion criteria were as follows: teeth
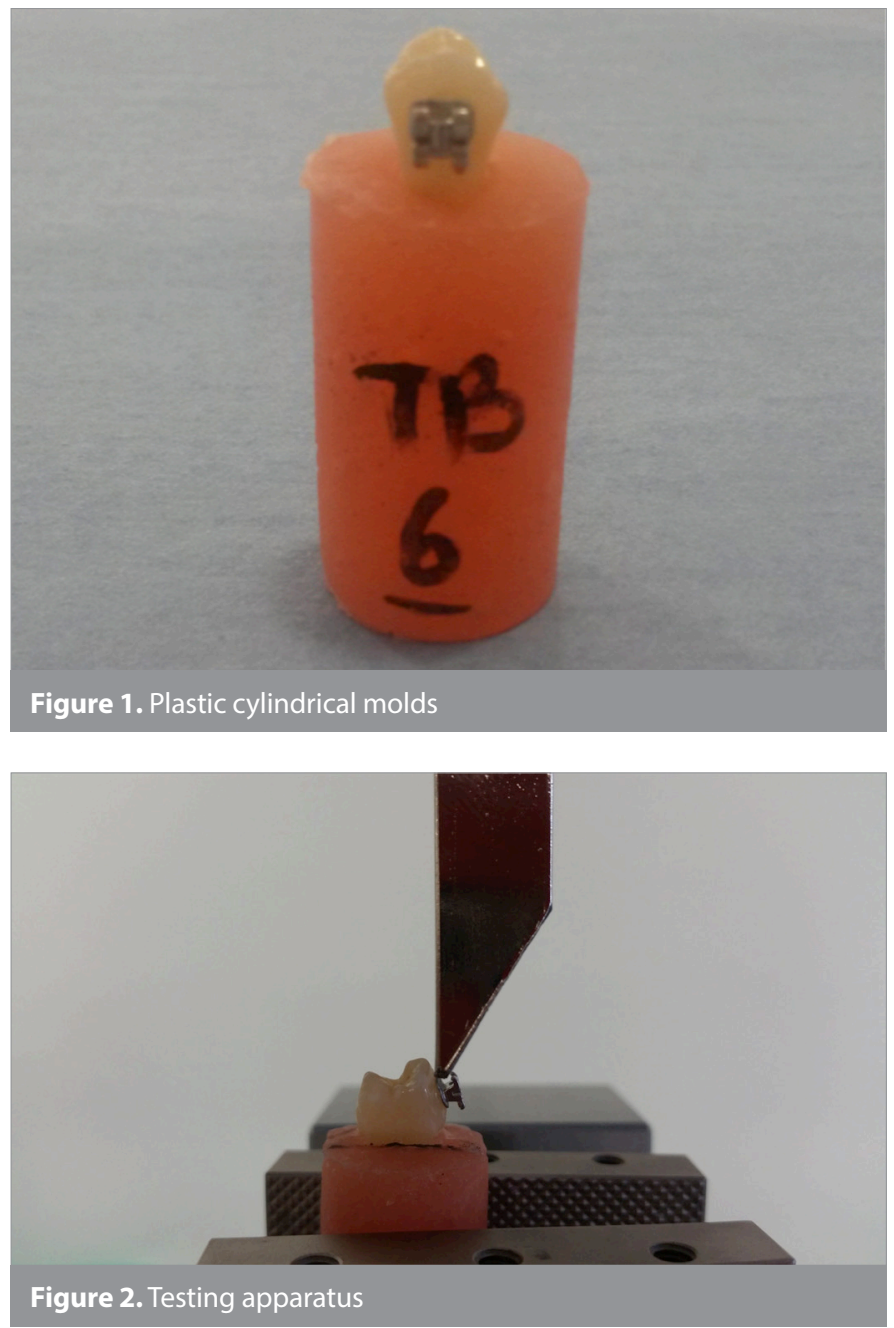

were not extracted for periodontal purpose and teeth with no caries, no filling or restoration, no crack on the surface of the enamel, and no malformation on the vestibule surface. The study was approved by the Research Ethics Committee of İstanbul Medipol University. (protocol no. 10840098-604.01.01-E.5731, 21/04/2016).

The enamel surfaces were assessed before the experiment by using a stereomicroscope (SZX10; Olympus, Japan) at 10× magnification, and the teeth that did not meet the criteria were excluded from the study. The teeth were washed to remove organic debris and were kept in a $0.1 \%$ thymol solution to prevent degradation of the enamel structure and bacterial colonization.

\section{Preparation of Acrylic Molds}

The teeth were removed from the thymol solution, washed, and dried, and grooves were opened using a diamond bur on the root surface to provide retention before embedding to acrylic blocks. The teeth were embedded in acrylic blocks vertically to the ground, and the long axis of the teeth up to $1 \mathrm{~mm}$ apical of the cement-enamel junction was exposed (Figure 1). Plastic cylindrical molds with a $25 \mathrm{~mm}$ inner diameter and $30 \mathrm{~mm}$ height were used to prepare acrylic blocks. The vestibule surfaces of the teeth were brushed with a micromotor for $15 \mathrm{~s}$ using a soft brush and a fluoride-free pumice, washed for $15 \mathrm{~s}$, and then dried. The teeth were treated with $37 \%$ phosphoric acid, each bonding material was applied in accordance with the manufacturer's instruction, and then all of the brackets were bonded with Transbond XT adhesive (3M Unitek, Monrovia, CA, USA). Light curing of the adhesive was performed for $20 \mathrm{~s}$ using 3M Espe Elipar S10 (3M ESPE, Seefeld, Germany). Brackets were bonded with Transbond XT (3M Unitek) in group 1, with Clearfil SE Protect Bond (Kuraray Medical Inc., Tokyo, Japan) in group 2, with LED Proseal (Reliance Orthodontics, IL, USA) in group 3, and with Opalseal (Opal Orthodontic; Ultradent, South Jordan, UT, USA) in group 4. After bonding of the brackets, all groups were kept in distilled water at room temperature for 24 hours and then subjected to thermocycling with a thermal cycler (SD Mechatronik Thermocycler THE-1100; Feldkirchen-Westerham, Germany). The samples were immersed in water baths at temperatures between $5^{\circ} \mathrm{C}$ and $55^{\circ} \mathrm{C}$ for 1000 times. The samples were set to have a waiting time of $30 \mathrm{~s}$ and a transfer time of $5 \mathrm{~s}$ in each bath.

\section{SBS Test}

SBS tests were performed by a Universal Test Machine (Shimadzu Autograph AGS-X, Japan) at a crosshead speed of $1 \mathrm{~mm} / \mathrm{min}$ loading on bracket-tooth interface by using a $0.5 \mathrm{~mm}$ thickness blade $\left(60^{\circ}\right.$ cut end face, Shimadzu toothed pushrod B, Japan) (Figure 2). The specimens were placed as their long axis was vertical to the ground and fixed in the mesiodistal direction by using two screw plates to avoid their rotational movement. The force at debonding of the bracket was recorded in Newton (N); thereafter, the results were converted to megapascals ( $\mathrm{MPa}$ ) by dividing the force value $(\mathrm{N})$ into the bracket base area $\left(\mathrm{mm}^{2}\right)$. The bracket surface area was $11.98 \mathrm{~mm}^{2}$ according to the manufacturer's instruction. The buccal surfaces of the teeth were assessed using a camera of a stereomicroscope (SZX10; Olympus) at 20X magnification. Residual adhesive on the teeth surface was classified using the Adhesive Remnant Index (ARI) (13). The ARI scores were as follows: 0 : no adhesive residue on the tooth, $1:<50 \%$ of 
adhesive remains on the tooth, $2:>50 \%$ of adhesive remains on the tooth, and 3: all the adhesive remains on the tooth (Figure 3).

Two samples from each group were examined at $40 \times$ and $250 \times$ magnification by using a scanning electron microscope (Zeiss EVO LS 10; Carl Zeiss, Oberkochen, Germany) (Figure 4-7).
A2

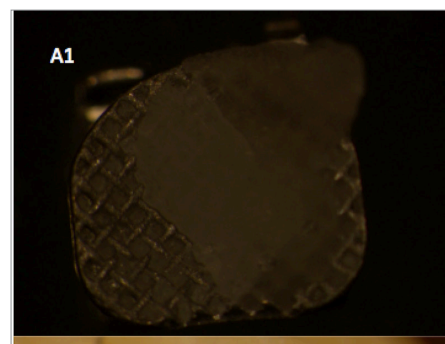

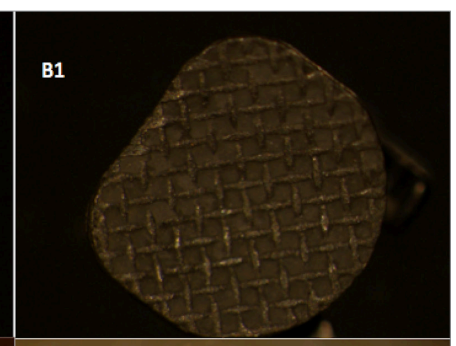

B2
Figure 3. a, b. ARI views of the sample brackets and teeth.

(A1) ARI 1 score bracket view. (A2) ARI 1 score tooth view. (B1) ARI 2 score bracket view. (B2) ARI 2 score tooth view
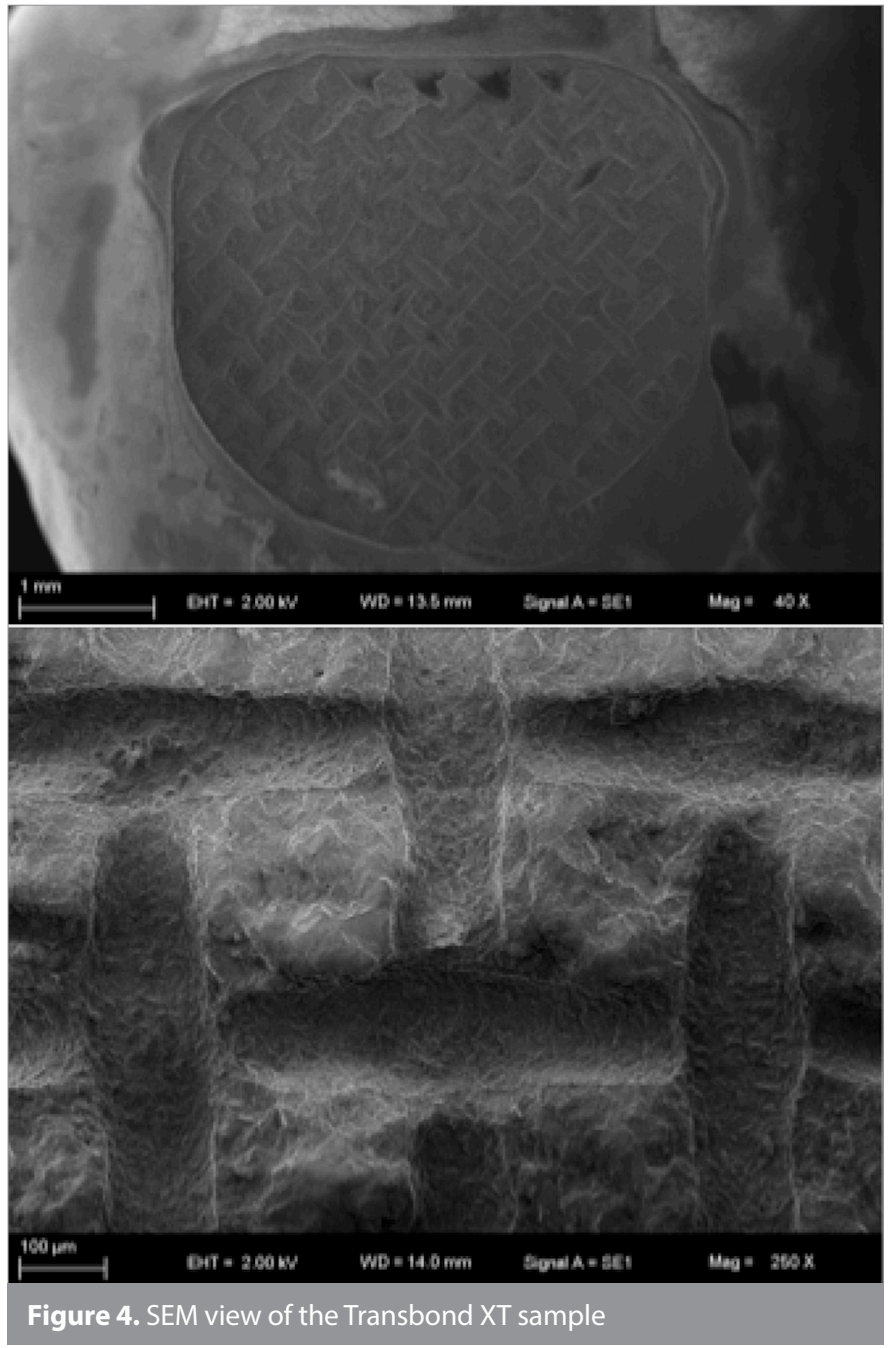

\section{Statistical Analysis}

Data were evaluated by Statistical Package for Social Sciences version 22.0 (IBM Corp.; Armonk, NY, USA). Shapiro-Wilk test was used to evaluate the normality of the data. One-way analysis of variance (ANOVA) test was used to compare group differences. Tukey HSD (Honestly Significant Difference) test was used for post-hoc comparisons. Chi-square and Fisher's exact tests were used to evaluate qualitative data. A p value $<0.05$ was considered as significant.

\section{RESULTS}

\section{SBS Test Results}

The results of SBS tests are given in Table 1. There was no statistically significant difference in SBS between the groups $(p=0.067)$. The Opalseal group showed the highest bond strength (12.56 \pm 2.32$)$. The lowest bond strength was measured in the Proseal group (10.66 \pm 2.06$)$.

\section{ARI Scores}

The results of ARI scores are given in Table 2. There was a statistically significant difference between the groups with respect to ARI scores $(p=0.016$ and $p<0.05)$. There were no ARI scores of 0 and 3.

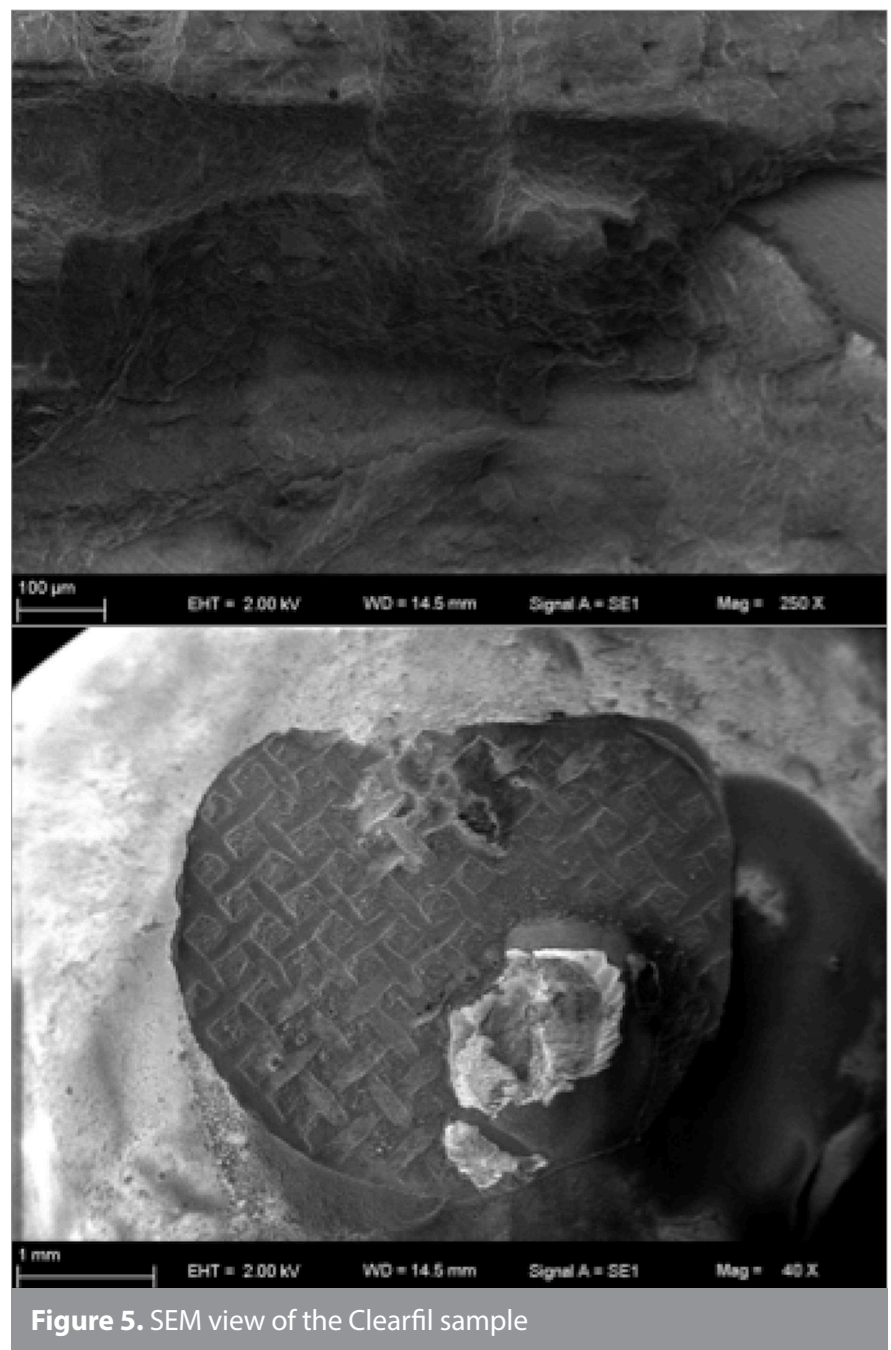




\section{DISCUSSION}

Fluoride-containing materials are widely used to prevent WSLs in orthodontic practice. It is possible to measure the bond strength of brackets in in vivo and in vitro conditions. Murray and Hobson reported that there is a difference in force values between these two conditions in their study (14). The mean bond strength values of brackets were found to be $9.78 \mathrm{MPa}$ in vitro and 14.34
MPa in vivo. Researchers have usually preferred to perform in vitro bond strength tests instead of in vivo ones because of the difficulty of intraoral measurements of bond strength (10-12). Therefore, bond strength values were measured in vitro in the present study.

The incisor, premolar, and molar teeth can be used in SBS tests $(10-12,15)$. Human premolar teeth were used in the present

\begin{tabular}{|c|c|c|c|c|c|c|}
\hline & \multirow{2}{*}{$\begin{array}{l}\text { One-way ANOVA } \\
\text { Shear bond strength } \\
\text { (MPa) Mean } \pm \text { SD }\end{array}$} & & \multicolumn{4}{|c|}{ Tukey HSD } \\
\hline & & & Mean difference & $95 \% \mathrm{Cl}(\mathrm{min})$ & $95 \% \mathrm{Cl}(\max )$ & $\mathbf{p}$ \\
\hline Transbond XT & $11.55 \pm 3.06$ & Transbond XT-Clearfil & 0.800 & -2.875 & 1.275 & 0.743 (NS) \\
\hline Clearfil & $10.75 \pm 2.70$ & Transbond XT-Opalseal & 1.010 & -1.065 & 3.085 & 0.580 (NS) \\
\hline Opalseal & $12.56 \pm 2.32$ & Transbond XT-Proseal & 0.890 & -2.965 & 1.185 & 0.675 (NS) \\
\hline \multirow[t]{2}{*}{$p$} & 0.067 (NS) & Clearfil-Proseal & 0.090 & -2.165 & 1.985 & 0.999 (NS) \\
\hline & & Opalseal-Proseal & 1.900 & -3.975 & 0.175 & 0.084 (NS) \\
\hline
\end{tabular}
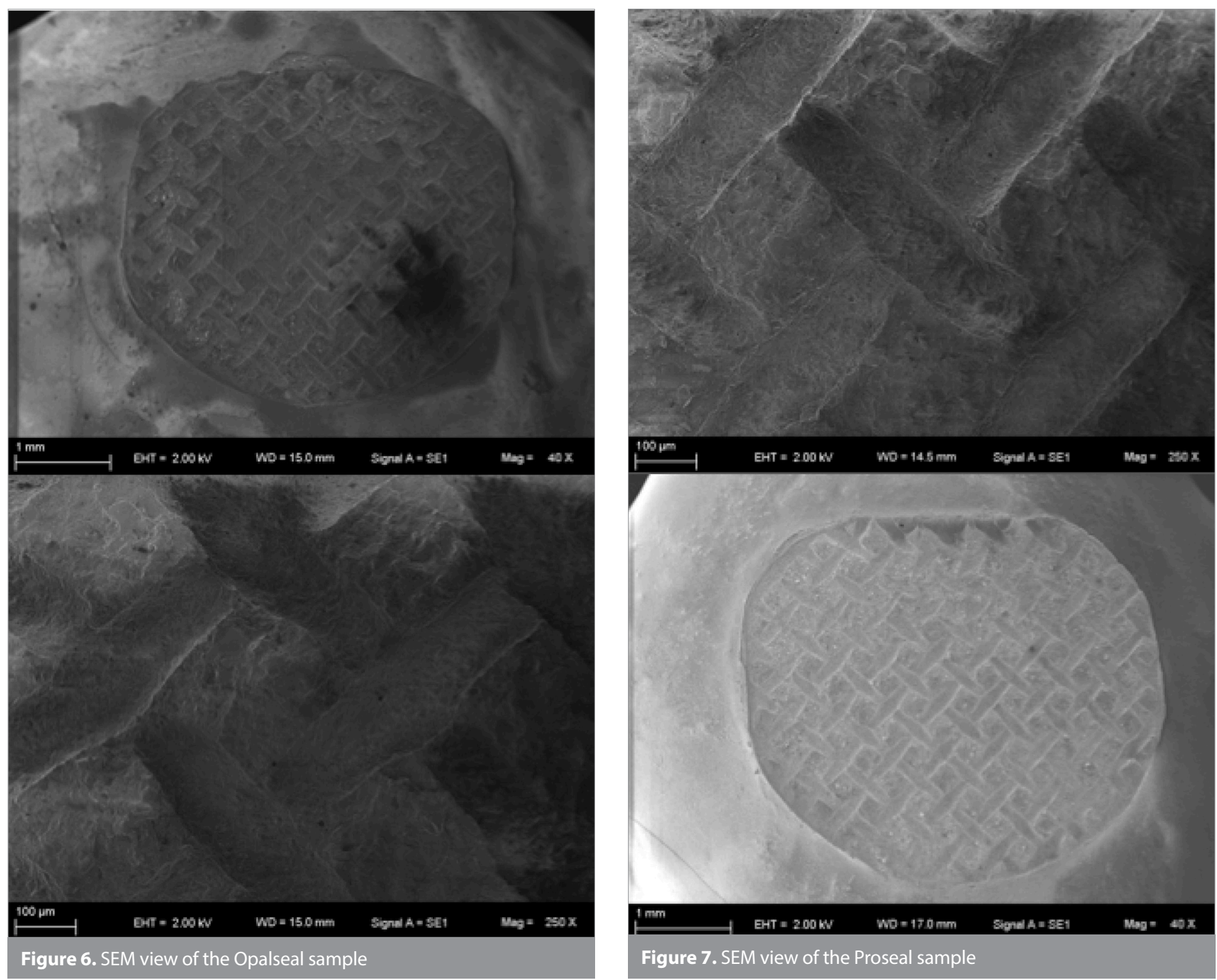
Table 2. Comparison of ARI scores between the groups based on

Fisher's exact and chi-square tests

\begin{tabular}{|lcccc|}
\hline & \multicolumn{4}{c|}{ ARI scores n (\%) } \\
\cline { 2 - 5 } & $\mathbf{0}$ & $\mathbf{1}$ & $\mathbf{2}$ & $\mathbf{3}$ \\
\hline Transbond XT & $0(0)$ & $5(23.8)$ & $16(76.2)$ & $0(0)$ \\
Clearfil & $0(0)$ & $0(0)$ & $21(100)$ & $0(0)$ \\
Opalseal & $0(0)$ & $0(0)$ & $21(100)$ & $0(0)$ \\
Proseal & $0(0)$ & $4(19)$ & $17(81)$ & $0(0)$ \\
\hline * $<<0.05$. & & & & \\
\hline
\end{tabular}

study because they can be easily obtained by orthodontic extractions.

Dental materials are subjected to thermal, mechanical, and chemical stresses in the mouth. Applying thermal cycle or water retention process to the dental materials allows to simulate oral conditions. Application of thermal cycling was previously reported to make a decrease in SBS values (16-18). The thermal cycling was usually conducted between $5{ }^{\circ} \mathrm{C}$ and $55^{\circ} \mathrm{C}$ in different numbers of cycle, such as 500, 1000, 2000, 10,000, and 20,000. Bisha-

ra et al. (19) demonstrated that there is a significant reduction in bond strength of a cyanoacrylate-containing adhesive up to $80 \%$ after 500 cycles of thermal cycling. However, Hasegawa et al. (20) suggested that the effect of 500 rounds of thermal cycling will not be sufficient to change the bond strength. In light of this knowledge, 1000 rounds of thermal cycle between the temperatures of $5{ }^{\circ} \mathrm{C}$ and $55^{\circ} \mathrm{C}$ were applied to the specimens in the present study.

Different brands of universal testing machines were previously used for SBS tests (10-12). The angle and the speed of the blade can change the reliability of SBS tests. As the angle of the applied force changes, the SBS is also affected. Klocke and Kahl-Nieke (21) reported that as the blade angle changes from $+15^{\circ}$ to $-45^{\circ}$, the connection force values decrease from 22.9 MPa to $6.65 \mathrm{MPa}$. In our study, the parallelism of the blade to the long axis of the bracket was checked before each force application. Bishara et al. (22) stated that if the blade speed decreases from 5 to $0.5 \mathrm{~mm} /$ $\mathrm{min}$, the bond strength increases from 7 to $12.2 \mathrm{MPa}$. The test reliability of in vitro studies decreases as the blade speed increases; therefore, we used a blade with a crosshead speed of $1 \mathrm{~mm} / \mathrm{min}$ $(10-12,23)$.

Reynolds (2) stated that the bond strength values of the brackets should be in the range of 5.9-7.8 MPa or above in clinical and 4.9 $\mathrm{MPa}$ in laboratory conditions. Enamel fracture strength was known as $14 \mathrm{MPa}$, and it was reported that an increase in the risk of enamel fracture can be seen over the value of $10 \mathrm{MPa}$. The desired mean values of SBS were criticized in previous studies, but no consensus was present in the literature (25-27). All groups in our study provided sufficient SBS values.

Artun and Bergland (13) defined the ARI score to assess the adhesive remnants, which is still widely used today, and in our study, the original ARI score was performed $(12,23,28,29)$. The failure type is not only related with the applied debonding force but also related with the type of the adhesive and the bracket base design (29). In our study, although statistically significant differences were observed in ARI scores between the groups, the results were generally concentrated in ARI 2 score. Although bonding materials were different, the use of the same bracket and adhesive might have an effect on the similarity of ARI scores. The ARI 2 score shows that debonding occurred at the bracketadhesive interface. Bishara et al. (30) advocated the failure that occurred in the bracket-adhesive interface and stated that this type of debonding can reduce enamel fractures.

The results of our study were compared with other similar studies in the literature. However, the lack of standardization in many factors, such as the type of teeth, storage conditions, preferred acid type, type of the adhesive, bracket type, light curing device, and light curing time, whether thermal cycle is applied or not, and the crosshead speed of the test device prevented us to perform the precise comparison. Korbmacher et al. (23) compared the SBS values of a conventional bonding agent (Transbond XT) with fluoride-releasing self-etching primer (Clearfil Protect Bond, CPB) and found that SBS results and ARI scores of their study were consistent with our study. Arhun et al. (31) evaluated the SBS values of Adper Prompt L-Pop (3M ESPE, St. Paul, MN, USA) selfetch adhesive, CPB, and Transbond plus self-etching primer (3M Unitek) in their study and found a significant difference between the groups. CPB showed the highest SBS value of $13.85 \pm 4.32 \mathrm{MPa}$. Although the etching process was not performed before application, the SBS values of CPB was higher than that of our study. Application of thermal cycle might have decreased the bond strength in this study. Tuncer et al. (10) assessed the SBS values of Transbond Self-etching Primer (3M Unitek) and Ortho-Coat, CPB, and CPB+Ortho-Coat. The mean SBS value of the CPB group was $13.48 \pm 1.78 \mathrm{MPa}$, which was higher than that of our study, and this result can be attributed to the absence of thermal cycle in their study. No significant difference was observed in ARI scores between the groups, and the majority of the failures were in the enamel-adhesive interface in contrast to our study. Minick et al. (28) used Aegis Ortho (Bosworth Co., LL, USA), CPB, iBond, Clearfil S3 Bond (Kuraray, USA), and Transbond XT (3M Unitek) combined with metal brackets and bovine teeth in their study. Transbond XT showed 10.05 $\pm 0.84 \mathrm{MPa}$, and CPB showed a $7.5 \pm 0.79 \mathrm{MPa}$ bond strength exactly after bonding. The specimens that were tested after $24 \mathrm{~h}$ showed $10.11 \pm 1.02 \mathrm{MPa}$ and $6.09 \pm 0.56 \mathrm{MPa}$ SBS values, respectively. Lower SBS values of samples may be related to the use of bovine teeth in that study. On the other hand, CPB showed clinically sufficient bond strength values, and the ARI scores were similar to our study. Raji et al. (32) assessed the SBS values of Transbond $\mathrm{XT}$ and $\mathrm{CPB}$, and they could not find a significant difference between the groups. The SBS values and ARI scores of their study were consistent with our study. Soake et al. (33) evaluated the SBS values of Clearfil SE, CPB, Prompt L-Pop, and Reliance self-etching primer and found that the mean SBS value of CBP is $11.94 \pm 2.74$ $\mathrm{MPa}$, which was similar to our study.

Bishara et al. (34) investigated the effects of Proseal on the bond strength of orthodontic brackets comparing with conventional bonding agent, and no significant difference was found between the groups. Furthermore, the mean SBS value of the Proseal group was found to be $4.8 \pm 2.3 \mathrm{MPa}$. Although the SBS value of Proseal 
was clinically sufficient, it was quite low compared with the SBS value in this study. This difference may have been related to the application of SBS tests exactly $30 \mathrm{~min}$ after bonding of the brackets and use of molar teeth in that study. Paschos et al. (35) assessed conventional and self-etch adhesive systems whether they affect the bond strength. As a result, they found that the use of Proseal had no negative effect on the bond strength. The bond strength of Proseal after 500 cycles of thermal cycling showed a very close result $(10.8 \pm 2.9 \mathrm{MPa})$ to our findings. Similar to our study, the ARI scores were concentrated in 2 scores. Varlik and Ulusoy (36) reported that Proseal does not have a significant effect on the SBS values of any group in their study. The Proseal-metal bracket combination group presented a mean value of $6.65 \pm 1.01 \mathrm{MPa}$, which was lower than that of our results. This difference may have originated from the use of different types of bracket and adhesive.

Hofmann et al. (37) combined three different kinds of fluoride-releasing bonding materials and a conventional bonding agent (Transbond XT) with four different kinds of orthodontic brackets. Similar to our study, they stated that all bonding materials presented adequate SBS values for clinical application. Furthermore, Transbond XT showed the highest SBS values among the other fluoride-releasing agents.

Kirschneck 2019 et al. (38) used Proseal in their prospective splitmouth study, and they stated that the use of enamel sealant before bracket bonding may increase the probability of bond failure especially in the lower jaw. They concluded that it is more suitable to use fluoride-releasing materials adjacent to the brackets after bracket bonding.

The nature of the present study was a limitation, and in vivo studies would provide more precise knowledge about this issue.

The study would be more valuable if the calcium and fluoride mass of the enamel could be measured with energy dispersive $\mathrm{X}$-ray microanalysis.

\section{CONCLUSION}

- There was no statistically significant difference between mean SBS values of the Transbond XT, Clearfil SE Bond, Opalseal, and LED Proseal groups. The null hypothesis was accepted.

- The highest SBS values were measured in the Opalseal group, followed by the Transbond XT, Clearfil SE Protect Bond, and Proseal groups, respectively.

- The bond strength of all groups were above the desired SBS value of 6-8 MPa.

Ethics Committee Approval: Ethics committee approval was received for this study from the Research Ethics Committee of İstanbul Medipol University (protocol no. 10840098-604.01.01-E.5731, 21/04/2016).

\section{Informed Consent: N/A.}

Peer-review: Externally peer-reviewed.
Author Contributions: Concept - G.S.; Design - GS.; Supervision - G.S.; Resources - D.Y.; Materials - D.Y.; G.S.; Data Collection and/or Processing - G.S., D.Y.; Analysis and/or Interpretation - G.S.; Literature Search - D.Y.; Writing Manuscript - G.S.; Critical Review - G.S.

Conflict of Interest: The authors have no conflict of interest to declare.

Financial Disclosure: The authors declared that this study has received no financial support.

\section{REFERENCES}

1. Buonocore MG. A simple method of increasing the adhesion of acrylic filling materials to enamel surfaces. J Dent Res 1955; 34: 84953. [CrossRef]

2. Sudjalim TR, Woods MG, Manton DJ. Prevention of white spot lesions in orthodontic practice: a contemporary review. Aust Dent J 2006; 51: 284-90. [CrossRef]

3. Gorelick L, Geiger AM, Gwinnett AJ. Incidence of white spot formation after bonding and banding. Am J Orthod 1982; 81: 93-8. [CrossRef]

4 Mizrahi E. Enamel demineralization following orthodontic treatment. Am J Orthod 1982; 82: 62-7. [CrossRef]

5. Geiger AM, Gorelick L, Gwinnett AJ, Griswold PG. The effect of a fluoride program on white spot formation during orthodontic treatment. Am J Orthod Dentofacial Orthop 1988; 93: 29-37. [CrossRef]

6. Lundström F, Krasse B. Streptococcus mutans and lactobacilli frequency in orthodontic patients; the effect of chlorhexidine treatments. Eur J Orthod 1987; 9: 109-16. [CrossRef]

7 Bishara SE, VonWald L, Laffoon JF, Warren JJ. Effect of a self etch primer/adhesive on the shear bond strength of orthodontic brackets. Am J Orthod Dentofacial Orthop 2001; 119: 621-4. [CrossRef]

8. Fjeld M, Øgaard B. Scanning electron microscopic evaluation of enamel surfaces exposed to 3orthodontic bonding systems. Am J Orthod Dentofacial Orthop 2006; 130: 575-81. [CrossRef]

9. Cossellu G, Lanteri V, Butera A, Laffi N, Merlini A, Farronato G. Timing considerations on the shear bond strength of orthodontic brackets after topical flüoride varnish applications. J Orthod Sci 2017; 6: 11-5. [CrossRef]

10. Tuncer C, Tuncer BB, Ulusoy C. Effect of fluoride-releasing lightcured resin on shear bond strength of orthodontic brackets. Am J Orthod Dentofacial Orthop 2009; 135: 14.e1-6; discussion 14-5. [CrossRef]

11. Korbmacher HM, Huck L, Kahl-Nieke B. Fluoride-releasing adhesive and antimicrobial self-etching primer effects on shear bond strength of orthodontic brackets. Angle Orthod 2006; 76: 845-50.

12. Faul F, Erdfelder E, Lang AG, Buchner A. G*Power 3: A flexible statistical power analysis program for the social, behavioral, and biomedical sciences. Behav Res Methods 2007; 39: 175-91. [CrossRef]

13. Artun J, Bergland S. Clinical trials with crystal growth conditioning as an alternative to acid-etch enamel pretreatment. Am J Orthod 1984; 85: 333-40. [CrossRef]

14. Murray SD, Hobson RS. Comparison of in vivo and in vitro shear bond strength. Am J Orthod Dentofacial Orthop 2003; 123: 2-9. [CrossRef]

15. Baysal A, Yasa A, Sogut O, Ozturk MA, Uysal T. Effects of different orthodontic primers on enamel demineralization around orthodontic brackets. J Orofac Orthop 2015; 76: 421-30. [CrossRef]

16. Elekdag-Turk S, Turk T, Isci D, Ozkalayci N. Thermocycling effects on shear bond strength of a self-etching primer. Angle Orthod 2008; 78: 351-6. [CrossRef]

17. Sokucu O, Siso SH, Ozturk F, Nalcaci R. Shear Bond Strength of Orthodontic Brackets Cured with Different Light Sources under Thermocycling. Eur J Dent 2010; 4: 257-62. [CrossRef] 
18. Al Jabbari YS, Al Taweel SM, Al Rifaiy M, Alqahtani MQ, Koutsoukis $\mathrm{T}$, Zinelis S. Effects of surface treatment and artificial aging on the shear bond strength. Angle Orthod 2014; 84: 649-55. [CrossRef]

19. Bishara SE, Ajlouni R, Laffoon JF. Effect of thermocycling on the shear bond strength of a cyanoacrylate orthodontic adhesive. Am J Orthod Dentofacial Orthop 2003; 123: 21-4. [CrossRef]

20. Hasegawa T, Retief DH, Russell CM, Denys FR. Shear bond strength and quantitative microleakage of a multipurpose dental adhesive system resin bonded to dentin. J Prosthet Dent 1995; 73: 432-8. [CrossRef]

21. Klocke A, Kahl-Nieke B. Effect of debonding force direction on orthodontic shear bond strength. Am J Orthod Dentofacial Orthop 2006; 129: 261-5. [CrossRef]

22. Bishara SE, Soliman M, Laffoon J, Warren JJ. Effect of changing a test parameter on the shear bond strength of orthodontic brackets. Angle Orthod 2005; 75: 832-5.

23. Korbmacher H, Huck L, Adam T, Kahl-Nieke B. Evaluation of an antimicrobial and fluoride-releasing self-etching primer on the shear bond strength of orthodontic brackets. Eur J Orthod 2006; 28: 45761. [CrossRef]

24. Reynolds IR. A review of direct orthodontic bonding. Br J Orthod 1975; 2: 171-8. [CrossRef]

25. Henkin FS, Macêdo ÉO, Santos KD, Schwarzbach M, Samuel SM, Mundstock KS. In vitro analysis of shear bond strength and adhesive remnant index of different metal brackets. Dental Press J Orthod 2016; 21: 67-73. [CrossRef]

26. $\mathrm{Oz} A A, O z A Z$, Arici $S$. In-vitro bond strengths and clinical failure rates of metal brackets bonded with different light-emitting diode units and curing times. Am J Orthod Dentofacial Orthop 2016; 149: 212-6. [CrossRef]

27. Finnema KJ, Ozcan M, Post WJ, Ren Y, Dijkstra PU. In-vitro orthodontic bond strength testing: a systematic review and meta-analysis. Am J Orthod Dentofacial Orthop 2010; 137: 615-22. [CrossRef]

28. Minick GT, Oesterle LJ, Newman SM, Shellhart WC. Bracket bond strengths of new adhesive systems. Am J Orthod Dentofacial Orthop 2009; 135: 771-6. [CrossRef]
29. O'Brien KD, Watts DC, Read MJ. Residual debris and bond strengthis there a relationship? Am J Orthod Dentofacial Orthop 1988; 94 : 222-30. [CrossRef]

30. Bishara SE, Oonsombat C, Ajlouni R, Laffoon JF. Comparison of the shear bond strength of 2 self-etch primer/adhesive systems. Am J Orthod Dentofacial Orthop 2004; 125: 348-50. [CrossRef]

31. Arhun N, Arman A, Sesen C, Karabulut E, Korkmaz Y, Gokalp S. Shear bond strength of orthodontic brackets with 3 self-etch adhesives. Am J Orthod Dentofacial Orthop 2006; 129: 547-50. [CrossRef]

32. Raji S, Ghorbanipour R, Majdzade F. Effect of clearfil protect bond and transbond plus self-etch primer on shear bond strength of orthodontic brackets. Dent Res J (Isfahan) 2011; 8: 94-9.

33. Sorake A, Rai R, Hegde G, Suneja R, Kumar N,Skaria J. Comparison of shear bond strength of new self-etching primer with conventional self-etching primers: An in-vitro study. J Int Oral Health 2015; 7: 1721.

34. Bishara SE, Oonsombat C, Soliman MM, Warren J. Effects of using a new protective sealant on the bond strength of orthodontic brackets. Angle Orthod 2005; 75: 243-6.

35. Paschos E, Okuka S, Ilie N, Huth KC, Hickel R, Rudzki-Janson I. Investigation of shear-peel bond strength of orthodontic brackets on enamel after using Pro Seal. J Orofac Orthop 2006; 67: 196-206. [CrossRef]

36. Varlik SK, Ulusoy C. Effect of light-cured filled bonding bonding of metal and ceramic brackets with a resin-modified glass ionomer cement. Am J Orthod Dentofacial Orthop 2009; 135: 194-8. [CrossRef]

37. Hofmann E, Elsner L Hirschfelder U, Ebert T, Hanke S. Effects of enamel sealing on shear bond strength and the adhesive remnant index: Study of three three fluoride-releasing adhesives in combination with metal and ceramic bracket. J Orofac Orthop. 2017; 78: 1-10. [CrossRef]

38. Kirschenck C, Rohn C, Proff P, Reicheneder C. Influence of enamel sealing with a light-cured filled sealant before bracket bonding on the bond failure rate during fixed orthodontic therapy. J Orofac Orthop 2019; 80: 136-43. [CrossRef] 